\title{
Sábato Magaldi vivo
}

[Sábato Magaldi alive

João Roberto Faria ${ }^{\mathrm{I}}$

Marcos Antonio de Moraes ${ }^{2}$

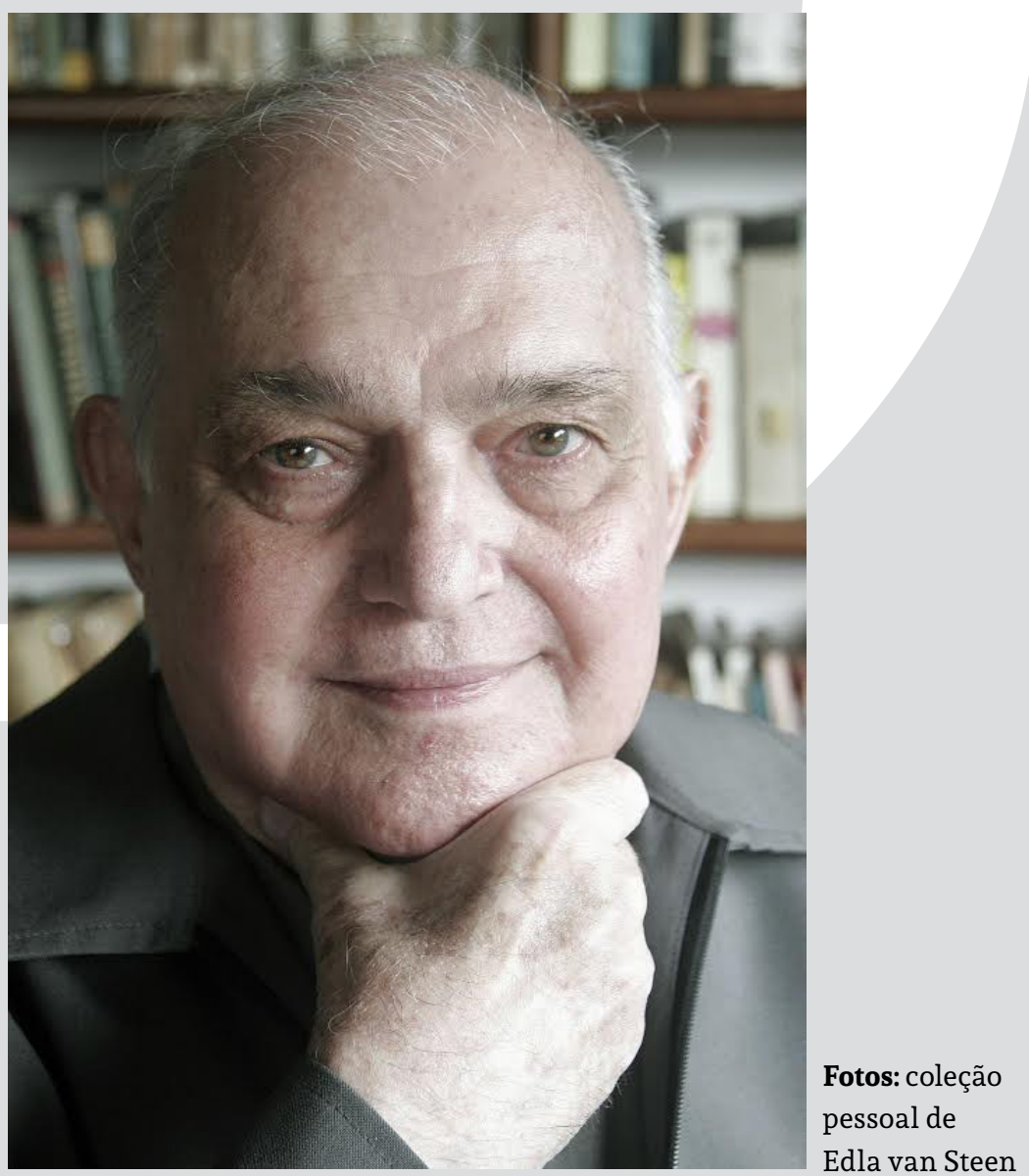

FARIA, João Roberto; MORAES, Marcos Antonio de. Sábato Magaldi vivo. Revista do Instituto de Estudos Brasileiros, Brasil, n. 68, p. 255-258, dez. 2017.

DOI: http://dx.doi.org/Io.II6o6/issn.23I6-90IX.voi68p255-258

I Universidade de São Paulo (USP, São Paulo, SP, Brasil).

2 Universidade de São Paulo (USP, São Paulo, SP, Brasil). 
Em I984, Sábato Magaldi elaborou uma substanciosa (e bem-humorada) nota biográfica, destinada a ocupar as páginas finais do livro Um palco brasileiro. O Arena de São Paulo, na saborosa coleção Tudo É História da Editora Brasiliense. Apresentava-se:

Nasci no dia 9 de maio de I927, em Belo Horizonte, sendo há algum tempo o decano da crítica teatral brasileira. Comecei em I950, no Diário Carioca, pelas mãos de Pompeu de Souza e Paulo Mendes Campos. Fui o titular da seção Teatro do Suplemento Literário de $O$ Estado de S. Paulo e sou[,] desde o primeiro número do Jornal da Tarde (I966), seu comentarista especializado.

Transferindo-me do Rio para São Paulo, a convite de Alfredo Mesquita, para lecionar História do Teatro, na Escola de Arte Dramática, depois de obter o certificado de Estética da Universidade de Paris (I953), leciono hoje na Escola de Comunicações e Artes da USP. Doutor em Letras, pela Faculdade de Filosofia, Letras e Ciências Humanas da USP, com uma tese sobre o teatro de Oswald de Andrade, tornei-me livre-docente de Teatro Brasileiro, na ECA, em I983, defendendo tese intitulada "Nelson Rodrigues: Dramaturgia e Encenações".

Publiquei, um tanto ao sabor de convites (a sobrevivência exigiu de mim melancólica dispersão), cinco livros: Panorama do Teatro Brasileiro, Temas da História do Teatro, Aspectos da Dramaturgia Moderna, Iniciação ao Teatro e O Cenário no Avesso (Gide e Pirandello). De parceria com Maria Thereza Vargas, escrevi Cem Anos de Teatro em São Paulo, ensaio que tomou quatro números do Suplemento do Centenário de $O$ Estado de S. Paulo. Ou por falta de tempo ou de interesse verdadeiro, não fiz ainda a revisão atual de pelo menos meia dúzia de volumes. Tarefa a que pretendo entregar-me, daqui por diante.

Diversamente da percepção do crítico, a sua obra está marcada por uma admirável coerência, em seu empenho em compreender o teatro, sua história e presença na vida cultural brasileira. De I984 em diante, a obra de Sábato se multiplicou, fazendo correr tinta nos jornais e cobrindo muitas páginas de livros. Nelson Rodrigues: dramaturgia e encenações (I987), O texto no teatro (I989), Moderna dramaturgia brasileira (I998), Cem 
anos de teatro em São Paulo (2000 - em parceria com Maria Thereza Vargas), Depois do espetáculo (2003), Teatro da obsessão: Nelson Rodrigues (2004), Teatro da ruptura: Oswald de Andrade (2004), Teatro sempre (2006) e Teatro em foco (2008) confirmam o seu compromisso com a dramaturgia brasileira, a história do nosso teatro, a teoria teatral e as ideias críticas. Além dos estudos específicos sobre Nelson Rodrigues e Oswald de Andrade, esses livros trazem dezenas de textos escritos para o Suplemento Literário d'O Estado de S. Paulo - geralmente sobre grandes dramaturgos universais -, palestras, resenhas, ensaios e artigos sobre os aspectos mais diversos da atividade teatral entre nós. Desse modo, Sábato cumpriu a promessa feita no final da nota autobiográfica anteriormente transcrita, publicando nove livros entre 1987 e 2008. Curiosamente, nenhum deles foi resultado direto do trabalho desenvolvido como crítico teatral. As análises dos espetáculos que viu ao longo de décadas ainda permaneciam nas páginas dos jornais, tanto do Rio de Janeiro, quanto de São Paulo.

Falecido em I4 de julho de 20I6, sua companheira de todos os momentos, a escritora Edla van Steen, foi quem se empenhou na organização e divulgação desses textos dispersos que, vistos em conjunto, constituem uma obra caudalosa, incontornável, um mapa seguro para os estudiosos do teatro brasileiro, em largo espectro. Mais que isso, uma boa parte desses textos contempla também a experiência de Sábato como espectador de montagens feitas por grandes encenadores europeus e norte-americanos. Em 20I4, Edla reuniu as críticas teatrais publicadas por Sábato no Jornal da Tarde, entre I966 e I988, num livro cujo título diz tudo sobre a relação do crítico com a arte à qual resolveu se dedicar: Amor ao teatro. Em impressionantes I.224 páginas, o volume traz 783 textos que comentam os espetáculos realizados por encenadores e artistas brasileiros, documentando assim o dia a dia de 22 anos da história recente do nosso teatro. Em 20I7, Edla fez mais uma compilação, desta vez de críticas teatrais que tratam de espetáculos apresentados por companhias e artistas estrangeiros em São Paulo, Rio de Janeiro e em cidades como Paris, Lisboa, Londres e Roma, entre outras. Com 200 textos, Na plateia do mundo introduz o leitor no universo dos grandes encenadores modernos, como Jean Vilar, Ariane Mnouchkine, Giorgio Strehller e Bob Wilson, para citar os mais importantes. Vale destacar que o volume reúne não apenas os textos escritos para o Jornal da Tarde, mas também os que foram publicados no Diário Carioca, entre I950 e I953.

Erudito, trabalhador incansável, de sociabilidade fácil, sem tergiversar em seus princípios estéticos, Sábato foi um entusiasta da modernização do nosso teatro, que acompanhou de perto. Dialogou o tempo todo com encenadores, dramaturgos e artistas, sempre tendo em mente o aprimoramento do nosso palco. Consciencioso, construiu uma obra crítica indispensável, que se lê com prazer, pois escrita com clareza e conhecimento profundo do teatro universal e brasileiro. Além do preparo intelectual, outra característica de Sábato pode ser lembrada: a honestidade com que desempenhou seu papel de crítico teatral. Num texto intitulado "Sobre a crítica" (Teatro em foco), espécie de profissão de fé, defendeu uma postura ética para o crítico, exigindo-lhe comedimento e urbanidade no texto, respeito aos artistas, ausência de preconceito e honestidade no julgamento dos espetáculos. Por essas razões, transitou, prestigiado, nos espaços jornalísticos, na Universidade, na Academia (Brasileira de Letras), nas salas de espetáculo. Sua memória encontra-se, de fato, viva. 
Edla van Steen, nesta homenagem da RIEB a um dos nossos maiores historiadores e críticos teatrais, resgata a memória íntima do companheiro de tantos anos, respondendo às perguntas dos professores João Roberto Faria, da Faculdade de Filosofia, Letras e Ciências Humanas da USP, e de Marcos Antonio de Moraes, do IEB. Edla, romancista, contista, dramaturga, tem em sua bibliografia um dos mais importantes testemunhos da vida literária brasileira, 39 entrevistas suas com escritores brasileiros, reunidas nos três volumes de Viver e escrever. Entrevistá-la, portanto, tornou-se um desafio. A trajetória pessoal e profissional de Sábato ganha colorido forte nessas memórias compartilhadas com generosidade.

Do Fundo Pessoal de Sábato Magaldi, em sua grande parte transferido recentemente para o Acervo de Escritores Mineiros, da Universidade Federal de Minas Gerais, publicamos a carta inédita que Mário de Andrade destinou a ele em I944, documento que Edla pretende doar ao IEB para se juntar a outras cartas do criador de Macunaíma. É um bonito documento de amizade e confiança na juventude, retrato do intelectual em formação.

\section{SOBRE OS AUTORES}

JOÃO ROBERTO FARIA é professor titular de Literatura Brasileira, vice-chefe do Departamento de Letras Clássicas e Vernáculas da Faculdade de Filosofia, Letras e Ciências Humanas da Universidade de São Paulo (FFLCH/USP) e integrante do Núcleo de Pesquisas Brasil-França (Nupebraf) do Instituto de Estudos Avançados (IEA/USP).

E-mail: igfaria@uol.com.br

MARCOS ANTONIO DE MORAES é professor de Literatura Brasileira do Instituto de Estudos Brasileiros da Universidade de São Paulo (IEB/USP) e organizador de Câmara Cascudo e Mário de Andrade. Cartas, I924I944 (2010).

E-mail:mamoraes@usp.br 